\title{
Determining the Pain-Affecting Factors of University Students with Nonspecific Low Back Pain
}

\author{
Ferruh Taspinar ${ }^{1)^{*}}$, Betul Taspinar $^{1)}$, Ugur Cavlak $^{2)}$, Erdal Celik $^{3)}$ \\ 1) Department of Physiotherapy and Rehabilitation, School of Health Science, Dumlupinar University: \\ Campus of Evliya Celebi, Kutahya, 43100, Turkey \\ 2) School of Physiotherapy and Rehabilitation, Pamukkale University, Turkey \\ 3) Sedat Tas Rehabilitation Centre, Turkey
}

\begin{abstract}
Purpose] This study was conducted on university students with nonspecific low back pain in order to determine the independent variables that affect their pain. [Methods] A total of 514 students were included in this study. Pain was evaluated using a Visual Analogue Scale (VAS). A special form was prepared in order to evaluate the following independent variables: gender, weight, height, Body Mass Index (BMI), working periods sitting straight (television, computer, seminar, etc.), working periods bending at a table (reading, writing, etc.), using lumbar support while sitting, the mean duration of pain within the last one year, type of pain, time of the pain, faculty, class, physical activity habits and smoking. The collected data were evaluated using the CHAID (Chi-squared Automatic Interaction Detection) analysis method. [Results] The working hours bending at a table, physical activity, height, weight, BMI and educational departments were found not to affect the severity of the pain. The pain severity was affected by the duration of pain complaints within the last one year, the duration of working staying upright, smoking, classes, usage of lumbar support and age variables. [Conclusions] The results of this study show that nonspecific low back pain of university students is affected by many factors such as smoking, class, age, using a computer and lumbar support.

Key words: Back pain, Risk factors, University students
\end{abstract}

(This article was submitted Apr. 16, 2013, and was accepted Jul. 3, 2013)

\section{INTRODUCTION}

Low back pain (LBP) is one of the most common problems in adolescents and adults ${ }^{1,2)}$. Many studies indicate that nonspecific low back pain in these individuals is caused by occupational factors. Many factors affecting low back pain such as anthropometric data in individuals' twenties, physiological structure, genetic factors, age, gender, smoking, the duration of working with a computer, lumbar support usage, school furniture, sitting position, physical activity, and socio-economic situations have been investigated $^{3,4)}$.

Although LBP is a physical and physiological disorder, it is commonly manifested as an occupational factor. Consequently, it causes disability and insufficiency while working ${ }^{5)}$. Moreover, it may be seen in school and university students who have not yet entered their working life, and may induce permanent symptoms ${ }^{6}$. The prevalence of LBP increases with an increase in classes ${ }^{7)}$. Many differ-

*Corresponding Author. Ferruh Taspinar (E-mail: fztferruh@ hotmail.com)

C2013 The Society of Physical Therapy Science

This is an open-access article distributed under the terms of the Creative Commons Attribution Non-Commercial No Derivatives (by-ncnd) License $<$ http://creativecommons.org/licenses/by-nc-nd/3.0/> ent factors affecting low back pain have been reported in the literature. However, the recent extraordinary increase in the data has made it difficult to process, evaluate and convert it into information. Thus, the aim of this study was to investigate the factors affecting nonspecific low back pain of university students, using the CHAID analysis method, which can examine much data at the same time.

\section{SUBJECTS AND METHODS}

A total of 514 (311 females and 203 males) university students with nonspecific low back pain, aged between 17 and 29 (Mean: 20.5 \pm 1.8 ) were included this study. The exclusion criteria were having any kind of musculoskeletal, orthopedic, rheumatic, somatic or psychiatric disorder. Subjects were selected from the Faculty of Medicine, Faculty of Engineering, Faculty of Science-literature, and Faculty of Education by a convenience sampling method. All gave their informed consent to participation in this study. The study was conducted in accordance with principles of the Declaration of Helsinki. A special questionnaire was created to investigate the pre-determined factors affecting nonspecific low back pain. These factors included gender, weight, height, BMI, working periods sitting straight (television, computer, seminar, etc.), working periods bending at a table (reading, writing, etc.), using lumbar support while 
sitting, the mean duration of pain within the last one year, type of pain, time of the pain, faculty, class, physical activity habits and smoking. These data and demographic data were recorded under the supervision of a physiotherapist. A visual analogue scale (VAS) was used to determine the severity of the pain. On the VAS scale, was indicated by the zero point, "no pain", and "unbearable pain" by the point of 100 on a vertical line of $100 \mathrm{~mm}$. The subjects marked their levels of sensed pain on this line. The reliability of this test was determined by Revill et al. in $1976^{8}$. The types of pain were chosen as combustive, stinging, obtuse and pulsative pains. In order to evaluate the durations of working hours bending at a table and staying upright, subjects were asked about their mean working hours in the last week. Subjects who used a lumbar support while sitting were determined. Smoking habits were noted as "smoker" or "non-smoker". Those who had quit smoking were included under the "smoker" category, and to determine the activity levels of the subjects, all subjects were asked to define themselves to be active or passive according to the criteria of our survey.

The data were entered into the SPSS 17.00 program. Categorical data were indicated as percentages. In order to determine how the variables explain nonspecific low back pain, the CHAID ( $\chi^{2}$ Automatic Interaction Detection) method of decision trees was used. The CHAID analysis is a method that determines the relations between the variables in the formed matches, and expresses the results in the shape of a tree and its branches. This analysis divides the data set of categorical variables into detailed homogeneous sub-groups that explain the dependent variable in the best way. It uses the $\chi^{2}$ significance test while performing the dependent grouping. When checking if the grouping of the variables is proper or not, it uses the Bonferroni recovered $p$ value ${ }^{9}$. For this study, nonspecific low back pain was determined as the dependent variable, and the independent variables that could explain the reason of the pain were examined.

\section{RESULTS}

A total of 514 students with nonspecific low back pain were evaluated: 229 (44.6\%) of them were from the Faculty of Medicine, $87(16.9 \%)$ of them were from the Faculty of Engineering, 104 (20.2\%) of them were from the Faculty of Education, and 94 (18.3\%) of them were from the Faculty of Science-literature. Their BMIs, departments, classes, physical activity, smoking status, usage of lumbar support, pain duration, working durations, and gender are shown as $\mathrm{n}$ and percentages in Table 1. Independent variables that could affect the "pain" dependent variable were identified by the analysis, which determined that working duration, bending at table, physical activity, gender, weight, height, BMI and educational department did not affect the pain.

The strongest associated variable was "duration of pain complaints within the last one year" $(p=0.000)$. The pain severity of students with pain lasting longer than one month was determined as the highest mean value, $5.95 \pm 1.69 \mathrm{~cm}$. The pain severity of students with pain lasting for a few days within the last one year was found to have the lowest
Table 1. Sample Characteristics

\begin{tabular}{|c|c|c|c|c|c|c|}
\hline \multirow{2}{*}{ Variables } & \multicolumn{2}{|c|}{ Boys } & \multicolumn{2}{|c|}{ Girls } & \multicolumn{2}{|c|}{ Total } \\
\hline & $\mathrm{n}$ & $\%$ & $\mathrm{n}$ & $\%$ & $\mathrm{n}$ & $\%$ \\
\hline \multicolumn{7}{|l|}{ Age } \\
\hline$<20$ & 58 & 28.6 & 103 & 33.1 & 161 & 31.3 \\
\hline $20-22$ & 113 & 55.7 & 181 & 58.2 & 294 & 57.2 \\
\hline$>22$ & 32 & 15.8 & 27 & 8.7 & 59 & 11.5 \\
\hline \multicolumn{7}{|l|}{ BMI } \\
\hline Underweight $<18.5$ & 8 & 3.9 & 57 & 18.3 & 65 & 12.6 \\
\hline Normal 18.5-25 & 165 & 81.3 & 236 & 75.9 & 401 & 78 \\
\hline Overweight $>25$ & 30 & 14.8 & 18 & 5.8 & 48 & 9.4 \\
\hline \multicolumn{7}{|l|}{ Faculty } \\
\hline Health & 70 & 34.5 & 159 & 51.1 & 229 & 44.6 \\
\hline Engineering & 68 & 33.5 & 19 & 6.1 & 87 & 16.9 \\
\hline Educational & 47 & 23.2 & 57 & 18.3 & 104 & 20.2 \\
\hline Art & 18 & 8.9 & 76 & 24.4 & 94 & 18.3 \\
\hline \multicolumn{7}{|l|}{ Class } \\
\hline First year & 52 & 25.6 & 62 & 19.9 & 114 & 22.2 \\
\hline Second year & 67 & 33 & 106 & 34.1 & 173 & 33.7 \\
\hline Third year & 39 & 19.2 & 68 & 21.9 & 107 & 20.8 \\
\hline Fourth year & 45 & 22.2 & 75 & 24.1 & 120 & 23.3 \\
\hline \multicolumn{7}{|l|}{ Physical Activity } \\
\hline Inactive & 113 & 55.7 & 214 & 68.8 & 327 & 63.6 \\
\hline Active & 90 & 44.3 & 97 & 31.2 & 187 & 36.4 \\
\hline \multicolumn{7}{|l|}{ Smoking } \\
\hline Ex-smoker or Smoker & 86 & 57.6 & 82 & 73.6 & 168 & 32.7 \\
\hline Non-smoker & 117 & 42.4 & 229 & 26.4 & 346 & 67.3 \\
\hline \multicolumn{7}{|l|}{ Lumbar support } \\
\hline Not used & 106 & 52.2 & 166 & 46.6 & 251 & 48.8 \\
\hline Used & 297 & 47.8 & 145 & 53.4 & 263 & 51.2 \\
\hline \multicolumn{7}{|l|}{ Duration of pain } \\
\hline A few days & 32 & 15.8 & 29 & 9.3 & 61 & 11.9 \\
\hline One week & 102 & 50.2 & 175 & 56.3 & 277 & 53.9 \\
\hline More than a week & 26 & 12.8 & 32 & 10.3 & 58 & 11.3 \\
\hline One month & 35 & 17.2 & 60 & 19.3 & 95 & 18.5 \\
\hline More than one month & 8 & 3.9 & 15 & 4.8 & 23 & 4.5 \\
\hline \multicolumn{7}{|c|}{ Working periods sitting straight (last week) } \\
\hline None & 7 & 3.4 & 2 & 0.6 & 9 & 1.8 \\
\hline $1-10$ hours & 23 & 11.3 & 36 & 11.6 & 59 & 11.5 \\
\hline 11-20 hours & 20 & 9.9 & 26 & 8.4 & 46 & 8.9 \\
\hline $21-30$ hours & 28 & 13.8 & 41 & 13.2 & 69 & 13.4 \\
\hline $31-40$ hours & 28 & 13.8 & 57 & 18.3 & 85 & 16.5 \\
\hline $41-50$ hours & 23 & 11.4 & 44 & 14.1 & 67 & 1.3 \\
\hline 50 over & 74 & 36.5 & 105 & 33.8 & 179 & 34.8 \\
\hline \multicolumn{7}{|c|}{ Working periods bending at a table (last week) } \\
\hline None & 21 & 10.3 & 15 & 4.8 & 36 & 7 \\
\hline $1-10$ hours & 49 & 24.1 & 70 & 22.5 & 119 & 23.2 \\
\hline 11-20 hours & 39 & 19.2 & 51 & 16.4 & 90 & 17.5 \\
\hline 21-30 hours & 27 & 13.3 & 61 & 19.6 & 88 & 17.1 \\
\hline $31-40$ hours & 30 & 14.8 & 34 & 10.9 & 64 & 12.5 \\
\hline $41-50$ hours & 10 & 4.9 & 27 & 8.7 & 37 & 7.2 \\
\hline 50 over & 27 & 13.3 & 53 & 17 & 80 & 15.6 \\
\hline
\end{tabular}

BMI: Body Mass Index 
mean value, $3.68 \pm 1.84 \mathrm{~cm}$. A short duration of pain in the last one year indicated low pain severity, and long duration indicated high pain severity.

In the students indicating a pain duration of one week or longer within the last one year, it was determined that working duration and sitting upright affected the severity of the pain $(\mathrm{p}=0.001)$. The severity of the pain was determined as $4.77 \pm 1.56 \mathrm{~cm}$ for the students whose working periods sitting straight were over 30 hours within the last week, and as $4.16 \pm 1.43 \mathrm{~cm}$ for $=$ students whose working periods sitting upright were less than 30 hours. These values indicate that the duration of working while sitting straight was a factor affecting both the duration and the severity of the pain.

The class variable affected the severity of the pain of the students working sitting upright for less than 30 hours in the last one week $(\mathrm{p}=0.000)$. In the first and second class students, $3.75 \pm 1.24 \mathrm{~cm}$ pain severity was determined, whereas in the third and fourth class students, $4.73 \pm 1.50 \mathrm{~cm}$ pain severity was determined. Lumbar support usage affected the pain of students who worked more than 30 hours sitting upright ( $\mathrm{p}=0.011$ ). The students who worked for long periods sitting upright not using lumbar support had a $5.10 \pm 1.53 \mathrm{~cm}$ pain severity, whereas students who used a lumbar support had a $4.46 \pm 1.53 \mathrm{~cm}$ pain severity.

The mean pain severity of the students whose pain lasted for one month within the last one year was $5.25 \pm 1.42 \mathrm{~cm}$. The "age" independent variable affected this variable $(p=0.003)$. The pain severity of students under 19 years was $4.51 \pm 1.37 \mathrm{~cm}$, whereas it was $5.57 \pm 1.32 \mathrm{~cm}$ those over 19 years. The smoking variable followed the age variable $(p=0.008)$. The pain severity was $5.77 \pm 1.28 \mathrm{~cm}$ in the smokers, whereas it was $4.66 \pm 1.15 \mathrm{~cm}$ in non-smokers.

\section{DISCUSSION}

We determined that pain duration within the last one year, working duration sitting upright, educational class, lumbar support usage, age and smoking habit affects the nonspecific low back pain severity of university students. The most important independent variables that may explain the "pain" were investigated using the decision tree technique. Many factors that may affect the pain have been reported in the literature. For example Alkherayf and Agbi reported a relationship between daily smoking amount and chronic LBP of young adults in $2009^{10)}$. Wang et al. reported a relationship between smoking and musculo-skeletal pain in 20111). Why smoking triggers LBP has not been clearly explained. However, in general it is known that bone mineral density is reduced by smoking, and osteoporosis may develop following this reduction, enabling micro-fractures to form in the vertebrae. Some researchers have suggested that this may cause degenerative changes in the vertebral column. Another suggestion is that coughing, that causes an increase in the intradiscal and intra-abdominal pressure, is increased by smoking. This pressure increase may cause disc herniation in some cases ${ }^{12}$. In our study, smoking appeared as a factor that increases nonspecific low back pain in university students. This result is similar to the results reported in the literature. However, the reasons for this ef- fect on nonspecific low back pain in this study are unclear, since the subjects were young adults showing no degeneration. Further studies need to conducted investigating the relationship of breathing problems with nonspecific low back pain.

The duration of sitting straight was another variable explaining nonspecific low back pain, and not using a lumbar support was determined as a factor increasing the pain. Previous studies have shown that ergonomic problems cause pain while working. In the study of Kanchanomia et al. of 524 university students, it was reported that physical risk factors and absence of a lumbar support while sitting straight had important roles in low back pain ${ }^{13)}$. Furthermore, low back pain was reported to be affected by age and gender. Wang et al. conducted a study in 2011 of 1,508 automobile workers, and reported that their musculo-skeletal problems were affected by bad ergonomics and excess weight ${ }^{11)}$. There are other studies in the literature that show a relation between obesity and low back pain ${ }^{14,15)}$. Similar to these studies, this study, too, showed a correlation between lack of a lumbar support, smoking and age factors. However, in contrast to the literature, weight was not a factor influencing low back pain. Since this was a study that included young adults, subjects with normal weights were the majority. Thus, weight did not affect low back pain. However, in elderly subjects it may be a variable that affects low back pain.

In the literature, there are studies which were conducted of university students from different departments which investigated low back pain according to department. This study also investigated students from different departments, as well as students of different classes. Moreder et al. determined no difference in low back pain of medicine and sports students. However, the prevalence of low back pain was $53.4 \%$ in medicine students, whereas it was $60.7 \%$ in sports students ${ }^{16)}$. In the study of Falavigna et al. of physiotherapy students (2011), a clear relationship was found between physiotherapy bachelor's level education and $\mathrm{LBP}^{17}$ ). They stated that the long periods of studying hours had an important effect on the onset of LBP. In another study of dentistry students, it was determined that the onset of lumbar, cervical and shoulder pain was seen when the students started their clinical practice training ${ }^{18)}$. It was previously reported that students of medical departments are at higher risk of low back pain than students of other departments. Although there are conflicting results in the literature, the present study did not find a difference between the students of physiotherapy and nursing and other departments, with regard to low back pain, and showed that the educational department was not a variable explaining low back pain. However, the "class" variable was a factor influencing low back pain, and it increased with the increase in classes. The reason may be students' undervaluing ergonomics. Because it was determined that the upper classes commonly had practical lessons, whereas the lower classes commonly had theoretical lessons.

Many previous studies were conducted in order to determine the reason for LBP in students. However, LBP is not dependent on only one reason, it is a multi-factorial disease. 
Thus, the analysis method should evaluate all the possible factors that may affect the pain. This study evaluated many factors that possibly affect low back pain at the same time.

The CHAID method used in this study is a method which still under development. Statistical methods in the literature generally compare several variables. However, CHAID makes it possible to compare many variables at the same time. Thus, such methods, which have more explanatory power, should be used more frequently, as they strengthen the validity of study results. University students with low back pain have been grouped as a single category, but they include cases with different pathologies and symptoms. Studies should be conducted following the formation of categories for different pathologies, symptoms and medical histories. These planned studies may result in more distinctive conclusions. Many factors that may cause low back pain were investigated in this study. However, psychological factors, other physiological factors such as posture, muscle strength or flexibility should also be investigated. These factors may depend upon the occupation of the subjects. Thus, subject characteristics should be included in the analysis in order to shed light in future studies.

Many factors cause nonspecific low back pain in university students. Age, smoking situations, classes, pain durations, sitting upright in front of monitors and disuse lumbar support are variables that affect nonspecific low back pain in students. In order to reduce or prevent nonspecific low back pain, students should be educated in their first classes and their smoking habits should be changed.

\section{REFERENCES}

1) Kelsey JL, White AA: Epidemiology and impact of low back pain. Spine, 1980, 5: 133-142. [Medline] [CrossRef]

2) Coyte PC, Asche CV, Croxford R, et al.: The economic cost of musculoskeletal disorders in canada. Arthritis Care Res, 1998, 11: 315-325. [Medline] [CrossRef]
3) Punnett L, Pruss-Utun A, Nelson DI, et al.: Estimating the global burden of low back pain attributable to combined occupational exposures. Am J Ind Med, 2005, 48: 459-469. [Medline] [CrossRef]

4) Hestbaek L, Korsholm L, Leboeuf-Yde C, et al.: Does socioeconomic status in adolescence predict low back pain in adulthood? A repeated crosssectional study of 4, 771 Danish adolescentes. Eur Spine J, 2008, 17: 17271734. [Medline] [CrossRef]

5) Ehrlich GE: Low back pain. Bull World Health Organ, 2003, 81: 671-676. [Medline]

6) Hoogendoorn WE, Bongers PM, de Vet HC, et al.: High physical work load and low job satisfaction increase the risk of sickness absence due to low back pain: results of a prospective cohort study. Occup Environ Med, 2002, 59: 323-328. [Medline] [CrossRef]

7) Hestbaek L, Leboeuf-Yde C, Kyvik KO, et al.: The course of low back pain from adolescence to adulthood. Eight-year follow-up of 9600 twins. Spine, 2006, 31: 468-472. [Medline] [CrossRef]

8) Revill SI, Robinson J, Rosen M, et al.: The reliability of a linear analogue for evaluating pain. Anaesthesia, 1976, 31: 1191-1198. [Medline] [CrossRef]

9) Kass GV: An exploratory technique for investigating large quantities of categorical data. Appl Stat, 1980, 29: 119-127. [CrossRef]

10) Alkherayf F, Agbi C: Cigarette smoking and chronic low back pain in the adult population. Clin Invest Med, 2009, 32: E360-E367. [Medline]

11) Wang ZX, Qin RL, Li YZ, et al.: The epidemiological study of work-related musculoskeletal disorders and related factors among automobile assembly workers. Zhonghua Lao Dong Wei Sheng Zhi Ye Bing Za Zhi, 2011, 29: 572-578. [Medline]

12) Kelsey JL: An epidemiological study of acute herniated lumbar intervertebral discs. Rheumatol Rehabil, 1975, 14: 144-159. [Medline] [CrossRef]

13) Kanchanomai S, Janwantanakul P, Pensri P, et al: A prospective study of incidence and risk factors for the onset and persistence of low back pain in Thai university students. Asia Pac J Public Health, 2011, 20. [Medline]

14) Deyo RA, Bass JE: Lifestyle and low-back pain the influence of smoking and obesity. Spine, 1989, 14: 501-506. [Medline] [CrossRef]

15) Rubin DI: Epidemiology and risk factors for spine pain. Neurol Clin, 2007, 25: 353-371. [Medline] [CrossRef]

16) Moroder $\mathrm{P}$, Runer $\mathrm{A}$, Resch $\mathrm{H}$, et al.: Low back pain among medical students. Acta Orthop Belg, 2011, 77: 88-92. [Medline]

17) Falavigna A, Teles AR, Mazzocchin $T$, et al.: Increased prevalence of low back pain among physiotherapy students compared to medical students. Eur Spine J, 2011, 20: 500-505. [Medline] [CrossRef]

18) Diaz-Caballero AJ, Gómez-Palencia IP, Díaz-Cárdenas S: Ergonomic factors that cause the presence of pain muscle in students of dentistry. Med Oral Patol Oral Cir Bucal, 2010, 15: e906-e911. [Medline] [CrossRef] 